\title{
The application of micro-lecture and flipped classroom in college english teaching
}

Zhiwei Liu

Foreign Language Department, Changchun University of Finance and Economics, Changchun 130000, China

\begin{abstract}
The concepts of micro-lecture and flipped classroom deriving from America have been formed for a long time and even get an obvious effect. Whether the two concepts can be used in college English course bothers the experts who have been working on the improvement of English class for many years. This article has insights into the concepts and applications about micro-lecture and flipped classroom. The article also serves as the research findings of the higher education reform project of Jilin province entitled "The Research and Practice of College English 'Flipped Classroom' Teaching Mode Based on Micro-Lecture” in 2016.
\end{abstract}

\section{Introduction}

Actually, college English teaching has been concerned for a long time. In recent years, the majority of universities in China are engaged to propose reform scheme about college English teaching, but they are all hardly effective. Obviously the reform is not the final target, because the aim of college English teaching is to cultivate the ability of using English according to the reality and provide talents to society. In fact, graded teaching is a main method applied in many universities last several years, but the capacity of different students in learning English are also various. Meanwhile, all teachers in college must have the same outline, same methods and even the same teaching system, so it is difficult for students to keep the flow of the course at the same pace totally. Apparently it is necessary for all of us to find out a new way to work it out.

\section{Concepts}

\subsection{Micro-lecture ------a kind of video carrier which can record the explanation of knowledge related to the content teachers are going to teach}

The rudiment of micro-lecture which is also called "60-Secind Course" was proposed by professor LeRoy A. McGrew, and then T. P. Kee also gave another definition called "The One Minute Lecture" which is short for OML. Nowadays it is put forward by David Penrose in 2008. In order to record a short video, the time maybe limited between 1-3 minutes. The key words as well as the important parts should be underlined in the video clearly. Students are required to learn them independently. Its core is to combine teaching contents and teaching aims together tightly. In web2.0 era, as the rapid development of information and communication (like Facebook, Youku, Tudou, blog etc), micro-lecture will be widely applied in education in the future. At the same time, the demand for English teacher is more and more severe than before, analyzing students must be placed at a high position while teachers are preparing their teaching classes. In a word, students must come first. In addition, teachers are asked to control the pace of classes, neither fast nor slow. Teachers also should master the skills of recording videos, such as how to design, how to remake, how to edit, and how to condense, etc. After experiencing the

process

of "study-practice-reflection-restudy-re-practice-re-i ntrospection", the ability of teaching and researching will be improved gradually.

As for students, micro-lecture can satisfy the various needs of students in learning different subjects. From micro-lecture, students can get what they want to gain. Besides, they can also make up for the deficiency of their English knowledge and intensify them effectively. Definitely, it is a kind of complement to the traditional classes as well as expansion. It is showed that it is easy for students to concentrate on learning English in ten minutes, in contrast to that, it is difficult for them to make it in traditional class for 45 minutes or more. So watching the short videos recorded by teachers maybe the most suitable method for students to learn independently, because they can control the time themselves. Through the micro-lecture, students could clearly get how other students understand about the same questions and widen their horizon further.

\subsection{Flipped classroom}

The model of flipped classroom was proposed by two

a Corresponding author: guotianbao1999@126.com 
chemists. The students would always be late due to the bad weather or body condition. In order to help students to keep up with the flow of the course, they videoed the content they were going to teach and uploaded them to internet for students to learn for free. A chief inspector of Intel called Brian Gonzalez considered that the flipped classroom was a virtually reversal form to the traditional class, as it provided more freedom to students and passed on knowledge to them outside of classroom. Everyone could choose the most suitable way to learn something new, and internalized them in classroom, therefore, there would be more communication and exchange between teachers and students. Over all, flipped classroom changes the college English teaching concepts, the roles of teachers and students as well as the teaching process.

The model of traditional class is that teachers explain the knowledge in class and then assign homework for students to finish at home. However, in the flipped classroom, students should be required to learn knowledge outside class and the traditional method in teaching knowledge in class will be replaced by discussions between teachers and students. In that way, Not only can the innovation and application about English knowledge be widened and broadened, but also the learning effect can be improved obviously. Last but not least, the essence of flipped classroom is to change the teaching method from "teaching first then learning" to "learning first then teaching".

\subsection{The relationship between micro-lecture and flipped classroom}

The flipped classroom should be based on the micro-lecture in order to be carried out smoothly. Because only do the students know the important knowledge and the main idea through the micro-lecture, the interaction between teachers and students in class can be effective. Therefore, the micro-lecture is an indispensable part of flipped classroom.

In conventional class, students get knowledge from teachers by looking at the blackboard on which the teachers write down all things related to their textbook with chalks. Doing homework is the only way to enhance their knowledge learned from class. But after watching the short video relevant to the knowledge, the discussion between teachers and student about the parts which confused students deeply are more helpful to students.

\section{The feasibility of flipped classroom}

\subsection{The features of flipped classroom}

Since many years ago, numbers of experts and scholars have been discussing how to teach effectively by videos, but they still do not find out the best method to change the status of the traditional class in teaching knowledge. But the appearance of flipped classroom drew much attention rapidly. The reasons are as follows.
Some researches show that human beings can only concentrate on learning something for 10 to 15 minutes, so the time of the video must be confined between 10 to 15 minutes. Otherwise, students could not sit in the front of the screen until the end of the video for a long time. Additionally, there must be only one vital language point in one video so that students can grasp the key point easily and effectively.

\subsubsection{The teaching information is specific}

It is known that in the traditional class, there are many elements such as the movement of teachers, the noise, even the tables and chairs may distract students from listening to teachers carefully. But if we record the knowledge in a video, those can be avoided to some degree.

\subsubsection{It's easy to check the learning outcome}

If the students want to make sure that whether they have remembered all the knowledge points after watching the video, the exercises are their best choices. By doing these exercises, students will effortlessly know the clear parts and the unclear parts. They can also go back to the video if necessary and contemplate them again and again, then the confusing parts will be worked out finally.

\subsection{The superiority of flipped classroom}

It is clear that memorization and comprehension are the main parts in traditional class. In fact, the grade of difficulty about those two parts is pretty low comparing with application, analysis and innovation in learning new knowledge. In addition, students are also asked to take these assignments home and complete them without any help. It is not reasonable for students to improve their learning skills. On the contrary, in the flipped classroom, teachers upload all the relevant videos to the internet, at the same time, students can learn new knowledge by watching them according to their own ability. They even can control the pace of learning without worrying about the places and times. Meanwhile, they can also communicate with their classmates about the difficult language points.

The functions of class and home are reversed by flipped classroom, in other words, memorization and comprehension will be achieved by students themselves, the rest parts mentioned before will be completed in class with the help of teachers. These are the remarkable advantages of flipped classroom.

Obviously, flipped classroom appeals to students to be the master of themselves in learning, and lets them know that the preparation should be placed at an important position in their mind when they plan to learn something new. It is also trying to break the original process of passing knowledge to students in traditional class, thus it is meaningful for everyone.

\subsubsection{The video is short but refined}




\section{The application of flipped class in college English teaching}

\subsection{The features of college English teacher}

Firstly, those who are teaching in college must have high academic qualifications and be easy to accept the new thoughts. The aim of teaching is to cultivate the students who can use the language independently, including the capacity of recreation and innovation. Generally speaking, the people who is good at doing research has a lively and active mind and be full of creativity. Being sensitive and logical can give an easy beginning and a solid foundation in carrying out the micro-lecture teaching system.

Secondly, in the era of cloud computing, teachers in college have mastered different kinds of means such as computer and media to teach English effectively. Furthermore, these skills are also necessary for teachers in college to record and edit videos accurately in order to help the students understand all the knowledge points easily and clearly.

\subsection{The features of college students in learning}

\subsubsection{Self-reliance}

Even though the students in college would learn things according to the teachers' requirement, they are really different from the students who finish their homework under the pressure of parents or teachers when they are in junior or senior middle school. Inversely, they have access to decide how to dominate their own time. The content in college class is fewer but better than before, despite that, the students are eager to read and learn more by themselves. Besides, there is no one who always tells the students in college what to learn or how to learn after class. What the student should do is just making their own plan on the basis of their own needs.

\subsubsection{Diversification}

Students could not study anything without learning in class which is regarded as the basic method when someone wants to have a further education, but it is not the only way like what they are in junior or senior middle school. The diverse ways for learning and colorful teaching activities have provided the really good circumstances to widen and broaden the knowledge students are going to learn. It also supplies enough time to carry out the micro-lecture system in college.

\subsubsection{Innovation}

Innovation is the soul of a state as well as the motivation of a country. As the subject of the innovation, the students are placed on more hopes to promote the development of society, to quicken the advancement of science and technology and to benefit all people in the world. Not only our country but also all the teachers working in the area of education are trying to create circumstances under which the students can study and innovate with freedom. As a matter of fact, the young people are more active, creative and innovative, and always leading the banner of the times ahead.

\subsubsection{The circumstances of college English learning}

At present, college students are going to learn English through the English class by watching the multimedia course-ware which is made and explained by teachers. There are also some interesting activities along with teachers' lessons. Besides that, students are eager to learn by themselves, and they can ask for help from teachers after school any time. The schedule could be even arranged reasonably, which means students can learn and prepare their class from internet independently after finishing the homework. Compare with traditional class, there are more advantages in the internet multimedia course-ware, which can combine pictures, voices, words and video together to make the English class more active and attractive. That is the foundation of flipped classroom and micro-lecture.

\section{The design of flipped classroom based on micro-lecture}

\subsection{The rules of designing}

In order to design the flipped classroom well, we should have enough theories to support our ideas. Besides, we must understand the entire process clearly, have insights into the features and obey the rules of flipped classroom, then it can be designed exactly.

\subsubsection{The process of designing flipped classroom}

The first step is to design the content of the class concisely, then record them in a video before having class. The second step is that students learn the new knowledge by themselves through the video at home and complete all the exercises related to the knowledge emphasized in the video. After finishing all the exercises, students may have a deep understanding about what they are going to get. But there must be some parts that students could not comprehend clearly or some parts they want to have a further study. Therefore the third step is to answer all the questions fully in class and debate with them to deepen and widen their knowledge learned from the video. What we should pay more attention is the content of the video. It must lead students to the right direction in learning English and enlighten them properly.

\subsubsection{The comprehension of the flipped classroom characteristic}

The flipped classroom changes not only the teaching structures but also the relationship between teachers and students. In the flipped classroom, teachers are not the ruler any longer, instead, they become the mentors and pushers participating in all the activities with students. 
Meanwhile, the roles of students in the flipped classroom are also changed from audience to participators and absolutely become more active and positive. The models of flipped classroom may be differed depending on different periods, different disciplines or different courses. But the basic concepts are much of a muchness. The effective flipped classroom must contain the following features: the passive listeners are transformed to the initiative learners; the flipped classroom could not be established without information technology; the knowledge structure in students' mind will be built with the help of various activities in flipped classroom; there is enough time in class to inspire students to challenge something more difficult, and cultivate the ability of dealing with practical problems.

\subsubsection{The rules in designing}

When we are going to design the flipped classroom, there are some rules should be obeyed.

Firstly, it must be good for establishing the knowledge structure and internalize them. Learning new knowledge will be done before class, while the discussion between teachers and students plays the most important role in class. Teachers become coordinators and mentors to stimulate students effectively.

Secondly, it must be beneficial for graded teaching. Different kinds of students need different knowledge in the same class. To good learners, it wastes plenty of time to learn something easy, while to learners, it is difficult for them to master the same knowledge. There is no balance in traditional class for good learners and poor ones. But in flipped classroom, it can be solved easily. Students could learn the knowledge from micro-videos according to their own time and needs without worrying about other students' schedule. Besides that they can also deepen their comprehension through watching videos again and again. It is convenient to the students who are at different levels.

Thirdly, it must be conducive to help students grasp new knowledge effectively. The teachers in flipped classroom are required to create circumstances under which students can learn things happily and easily. Students are never confined to regular time any more. They could control the pace until they finally gain all the new knowledge.

\section{Conclusions}

The combination between flipped classroom and micro-lecture is significant in embodying the educational concepts of "student-centered". The design of flipped classroom and the innovation of micro-lecture have been promoting the development of college English teaching. This kind of English teaching model gets acknowledged by experts and learners. Furthermore, it quickens the pace of application in college English teaching and embodies the social value gradually. According to the demand and analysis of college English teaching, the application of flipped classroom and micro-lecture will provide an effective method to deal with the problems confusing all teachers and students. In brief, it is significant to do more researches in improving the effects of college English teaching.

\section{References}

1. T.S. Hu, E-Education Research. 10, 61-65 (2011).

2. L.M. Liang, Q.Q. Cao, B.H. Zhang, Education Research. 02, (2013).

3. T.S. Hu, Q.C. Zhan, The Chinese Journal of ICT in Education, (2012).

4. H.L. Li, M.J. Deng, C.L. Liang, Modern Education Technology. 46-51 (2013)

5. M.X. Zhang. University Education, (2013). 